DOI 10.37882/2223-2982.2021.08.11

\title{
СУГГЕСТИЯ В МЕДИКО-ДИДАКТИЧЕСКОМ ДИСКУРСЕ: КОНЦЕПТЫ TORTOISE, TURTLE И ПРЕПОДАВАТЕЛЬ (НА МАТЕРИАЛЕ КОММУНИКАТИВНЫХ ПРАКТИК МЕДИЦИНСКОГО КОЛЛЕДЖА)
}

\section{SUGGESTION IN THE MEDICAL-DIDACTIC DISCOURSE: THE CONCEPTS OF TORTOISE, TURTLE AND TEACHER (BASED ON THE MATERIAL OF COMMUNICATIVE PRACTICES OF THE MEDICAL COLLEGE) \\ N. Dikun \\ I. Golubev \\ D. Demidenko}

Summary: This paper examines the medical and didactic discourse of the college and raises the question of the need to protect the of students' psychological health. The conceptual analysis of the zoonyms "tortoise" and "turtle", conducted first at the denotative level, and then at the three connotative sublevels (pagan, Old Testament and Christian), demonstrates the close connection of these concepts of fauna with that of the TEACHER, which contributes to the effective formation of a generalized semantic prototype of the latter, as well as sparing suggestive strategies.

Keywords: suggestion, medical-didactic discourse, psychological health of students, medical college, tortoise, turtle, teacher (lecturer), concept, generalized semantic prototype, sparing suggestive strategies.

\author{
Дикун Наталия Владимировна \\ К.филол.н., Тимашевский филиал ГБПОУ «Кущёвский \\ медицинский колледж» \\ chastity75@mail.ru \\ Голубев Илья Геннадьевич \\ Тимашевский филиал ГБПОУ «Кущёвский медицинский \\ колледж» \\ jkudjo@list.ru \\ Демиденко Дмитрий Александрович \\ Тимашевский филиал ГБПОУ «Кущёвский медицинский \\ колледж» \\ dimruss36@gmail.com
}

Аннотация:В настоящей работе рассматривается медико-дидактический дискурс колледжа и ставится вопрос о необходимости охраны психологического здоровья студентов. Концептуальный анализ зоонимов «tortoise» и «turtle», проведенный вначале на денотативном уровне, а затем - и на трех коннотативных подуровнях (языческом, ветхозаветном и христианском), демонстрирует тесную связь данных концептов фауны с концептом УЧИТЕЛЬ (ПРЕПОДАВАТЕЛЬ), что способствует эффективному формированию обобщенного семантического прототипа последнего, а также щадящих суггестивных стратегий.

Ключевые слова: суггестия, медико-дидактический дискурс, психологическое здоровье студентов, медицинский колледж, сухопутная черепашка, морская черепашка, учитель (преподаватель), концепт, обобщенный семантический прототип, щадящие суггестивные стратегии.

\section{Актуальность.}

Медико-дидактический или медико-педагогический дискурс [2] преподавателей и/или студентов колледжа соединяет в себе характеристики медицинского и педагогического типов дискурса, и такое специфическое гибридное промежуточное образование еще не было предметом лингвистического анализа.

Кроме того, происшедшие в XX веке в России социально-культурно-исторические сломы [3. С. 197] повлекли за собой увеличение факторов, подрывающих стабильность психологического здоровья студента, а особенно - первого курса [4. С. 65], когда за один учебный год приходится осваивать учебную программу 10 и 11 классов, что сопровождается естественным дискомфортом кризиса [5. С. 148] и потребностью аксиологического выбора [6. С. 111] на фоне стойко сохраняющихся черт подростковой психологии [ 7. С. 49; 8. С. 94]. Данное обстоятельство вызывает необходимость, как у преподавателей вузов, так и средне-специальных учебных заве- 
дений, участия в разработке совместной национальной профилактической стратегии [9. С. 87], направленной на формирование эффективных сочиооадаптивных навыков [10; 11].

Таким образом, актуальность данной работы обусловлена повышенным интересом современной науки к вопросам т.н. психологического здоровья подрастающего поколения, определяемого с 1979 года ВОЗ как «состояние душевного благополучия, отсутствие болезненных психических явлений» [12].

В обобщенном семантическом протоmune [13. С. 8] последнего, можно выделить следующие смысловые конституенты: адекватное поведение в обществе; полная реализация потенциала развития в различных видах деятельности (учебной, научно-исследовательской; игровой; профессиональной и т.n.); способность к симпатии, эмпатии и другие навыки межличностного общения; умение делать правильный выбор и нести за него ответственность, а самое главное, ощущение душевного комфорта.

Таким образом, цель данной исследовательской работы видится в определении уровня тревожности студентов I курса медицинского колледжа, их подверженности дидактогении, а также в создании обобщенного семантического прототипа идеального учителя и изучении под руководством преподавателя иностранного языка (английского) охранительных (щадящих) сугzестивных стратегий, которые будут способствовать т.н. профилактике невротических проявлений [14], вербальному утешению [15] обучаемых, а значит, их социальнопсихологической адаптации в социокультурном пространстве колледжа.

В работе были использованы как общенаучные методы (наблюдение, анализ, синтез, интерпретация, интроспекция), так и психологические (опрос информантов, метод беседы, а также психометрический анализ посредством шкал Спилбергера и Бека и статистическая обработка со значимыми различиями средних величин при $p<0,05)$. Кроме того, среди обучаемых была проведена оценка психической активачии, интереса, эмоционального тонуса, напряжения и комфортности с помощью соответствующей методики (Авторы: Н.А. Курганский, Т.А. Немчин) [16].

И наконец, в работе использовались методы лингвистического анализа - этимологический, дефиниционно-компонентный, кончептуальный, анализ лексической валентности, опрос информантов и дискурс-анализ.

\section{Результаты работы и их обсужление}

Исследование проводилось в Тимашевском (г. Тима- шевск Краснодарского края) филиале ГБПОУ «Кущёвский медицинский колледж» МЗ КК. Всего было обследовано около 100 студентов. Статистический анализ результатов измерения по шкале Спилберга и Бека подтвердил, что нарушения психологического здоровья обучаемых находятся в прямой зависимости от выявленных аффективных проявлений $(r=0,45 ; p<0,01)$. Среди последних наблюдалось преобладание тревожности (94,9 \% случаев), а также дидактогении (84,3\% случаев) как «брака педагогической работы» [17].

Были определены также уровни выраженности таких психических состояний первокурсников, как психическая активация (57\%), интерес (45\%), эмоциональный тонус (67\%), напряжение (96\%) и комфортность (21\%).

Установлено, что психологическое здоровье студентов колледжа определяется начинающейся профессионализачией [18] и профнавигацией [19], перспективной формой которых выступает студенческий научно-исследовательский кружок (СНИК). Так, в Тимашевском филиале ГБПОУ «Кущёвский медицинский колледж» был открыт такой кружок по дисциплине «ИНОСТРАННЫЙ ЯЗЫК» под названием MyEn before $U$, в рамках которого проводился научно-исследовательский семинар СУГГЕСТИЯ КАК ИНСТРУМЕНТ РЕЧЕВОГО ВОЗДЕЙСТВИЯ.

Рассмотрим английские лингвоконцепты tortoise (сухопутная черепашка) и turtle (морская черепашка), изученные нами во время работы СНИК. И начнем мы с понятийно-содержательного анализа, так как считается, что «с информологических позиций в тексте следует выделять» [20. С. 35] прежде всего «денотативный слой» [Там же].

На Среднем Западе США популярным развлечением во время ярмарок являются черепашьи бега, а во всём мире популярными домашними питомцами выступают различные виды некрупных сухопутных и пресноводных черепах. В Европе самые популярные виды - сухопутные черепахи, такие, как средиземноморская, балканская и среднеазиатская.

По одной из версий, предками черепах считаются пермские котилозавры -эвнотозавры (Eunotosaurus). Последние были очень похожи на ящерии, у них были короткие ноги и очень широкие рёбра, которые образовывали подобие спинного щита. Согласно второй версии, черепахи произошли от особой группы парарептилий - потомков дискозаврисков (амфибий). По последней, филогенетической версии, черепахи принадлежат к диапсидам с редуцированными височными окнами и к сестринской группе архозавров, представленным в современном животном мире крокодилами и птицами.

Известно множество ископаемых видов черепах, 
среди которых крупнейшими сухопутными черепахами были представители рода миолания (Meiolania) с длиной панциря около 2,5 м. При этом первая известная науке череnaxa Odontochelys semitestacea появилась 220 миллионов лет назад в мезозойскую эру в триасовый период. Она имела только нижнюю половину панциря и зубы во рту, что не характерно для современных черепах. Вторая по древности череnaxa Proganochelys quenstedti (210 миллионов лет назад, триасовый период) уже обладала полностью сформированным панцирем и также зубами.

В России в Международную Красную книгу внесена болотная череnaxa (Emys orbicularis) и средиземноморская череnaxa (Testudo graeca), последняя - также и в Красную книгу РФ в категории «1» и в приложение к Конвенции о международной торговле видами дикой фауны и флоры, находящимися под угрозой исчезновения.

Рассмотрев соответствующий британским лингвоконцептам TORTOISE и TURTLE русский лингвокультурный смысл ЧЕРЕПАХА в денотативном (содержательном) аспекте, перейдем к коннотативному (ассоциативному) слою.

Поскольку по окрасу и внешнему облику черепахи похожи на почву, в мифологии народов Африки в её образе изображается земля. Черепаха также выступает популярным персонажем африканских сказок, ей приписываются сверхъестественные способности и причастность к магии. В мифологии Китая рассматриваемое животное также играет роль символа: наряду с драконом, цилинем (единорогом) и фениксом, оно традиционно причисляется к т.н. четырём благопожелательным существам, а в доисторические времена, возможно, считалось и моделью мироздания. Не случайно каменные черепахи уже более полутора тысяч лет гордо украшают стелы китайских императоров, а в Испании и Италии прозрачные фонтаны. А 21 мая 2009 года в латвийском городе Даугавпилс был даже торжественно открыт памятник европейской болотной черепахе.

Если во время Второй мировой войны черепаха служила символом саботажа в борьбе польского Сопротивления (лозунг «работай медленно»), то современной молодёжи известны Великий А'Туин (вымышленная гигантская черепаха, на спине которой происходит действие в Плоском мире Терри Пратчетта), Лев-черепаха - персонаж мультсериала «Аватар: Легенда об Аанге», обучивший Аанга магии энергии, и Торатон - гигантская (размером с крупного динозавра-завропода) черепаха из 2-й серии фильма «Дикий мир будущего». Также чрезвычайно популярны черепашки-ниндзя - вымышленная команда четырёх антропоморфных черепах-мутантов.

Что касается раскрытия древней метафорической семантики этимона или внутренней формы зоонимов tortoise и turtle, она достаточно занимательна. Так как «понимание всегда даётся через образ» (Здесь и далее курсив - наш. - Д.Н., Г.И., Д.Д.) [21. С. 39], а мышление дискретно, предположим с большой долей вероятности, что окружающий мир подвергается в нем кониептуализации на трёх подуровнях сознания: языческом, ветхозаветном и христианском [22. С.156; 23. С. 5].

По данным этимологчческого словаря, зооним tortoise на языческом уровне (уровне внутренней формы) воспринимается как неведомая извивающаяся (TWISTING) сущность [24. С. 499]. В ветхозаветном происходит семантическое приращение: последняя становится большой ЯЩЕРИЦЕЙ [См. 25]. А в христианском - извивающаяся ящерица ложится в основу концепта TEACHER (УЧИТЕЛЬ), который (is being TORTURED) мучается сам на KPECTE и/или TORTURES his/her disciples (мучает своих учеников). Можно убедиться в этом, прочитав следующий фрагмент знаменитой ALICE IN WONDERLAND Льюиса Кэрролла:

"When we were little," the Mock Turtle (Здесь и далее курсив - наш. - Д.Н., Г.И., Д.Д.) went on at last, more calmly, though still sobbing a little now and then, "we went to school in the sea. The master was an old Turtle - we used to call him Tortoise -"

"Why did you call him Tortoise, if he wasn't one?" Alice asked.

"We called him Tortoise because he taught us," said the Mock Turtle angrily: "really you are very dull!"(Lewis Carroll, Alice's Adventures in Wonderland / Through the LookingGlass) [26].

В приведённом фрагменте наблюдается т.н. амфиболия, в данном случае семантическая двусмысленность или языковая игра, создающая эффрект комического [См. 27], что сохраняется в переводе самого произведения «В детстве я училась в самой модной - водной - школе. Учительницей у нас была тётя Черепаха (Здесь и далее курсив - наш. - Д.Н., Г.И., Д.Д.). Но мы её звали Черемама...По всем предметам были у нас Мучебники. Такие толстые, что читать их одно мучение. - И она тяжело вздохнула. - А ещё огромные, как киты, Китради. В них мы писали Жуквы, которые тут же расползались, и такие заковыристые Чихла, что от них свербило в носу и хотелось чихать...» [28]. Подобную идеологему, по данным Интернета, можно встретить в многочисленных названиях русских образцов дискурса прессы типа «Мучительница первая моя» [29]. «Суд оставил "учительничу-мучительницу" без зарплаты» [30].

Для сравнения, проведём трёхуровневый этимологический анализ номинанта морской черепашки TURTLE:

1. Языческий уровень: с одной стороны, опрокидывающаяся (capsizing) и всё время поворачивающаяся (turning) сущность, которую поэтому невозможно вывести 
из строя, парализовать, демобилизовать (incapacitate) и тем самым поймать, уловить, схватить (capture), а с другой это TURTLE-DOVE, т.е. ГОРЛИЦА - птица из рода ГОЛУБИНЫХ [См. 24. С. 509-510]. 2. Ветхозаветный: TWO TURTLE-DOVES - ПАРА ГОРЛИЦ, которую приносят в храм для принесения в жертву за ГРЕХ (См. библейскую аллюзию в тексте популярной британской рождественской песни: " On the second day of Christmas (Здесь и далее курсив - наш. - Д.Н., Г.И., Д.Д.) // My true love gave to me:// Two turtle doves// and a partridge in a pear tree... [31]. 3. Hoвозаветный: ИОАКИМ и АННА, дедушка и бабушка Христа, родители Пресвятой Богородицы, к которым в Акафисте

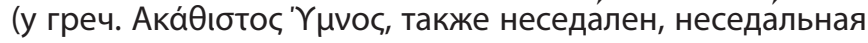
песнь, то есть «песнь, которую поют, не садясь, стоя - достаточно специфичном жанре православного церковного песнопения [См. 32]), обращаются подобным образом: «Радуйтеся, горлицы (Здесь и далее курсив - наш. - Д.Н., Г.И., Д.Д.) единосупружнии, голубичу непорочную произведшии [33. С. 11]

В современном английском языке также встречается лингвоконцепт TURTLE-NECK SWEATER (ВОДОЛАЗКА), который объективируется в результате своеобразной «семантической арифметики» номинантов: ОРНИТОНИМ (название птицЫ) + ОНИМ ОБЫЧНОГО ПРЕДМЕТА ОДЕЖДЫ + МЕДИЦИНСКИЙ ТЕРМИН = СВОЕОБРАЗНЫЙ ПРЕДМЕТ ОДЕЖДЫ.

Но вернемся к психологическому значению дидактических лингвоконцептов УЧИТЕЛЬ (УЧИТЕЛЬНИЦА) [СМ. 34; 35] и/иЛИ ПРЕПОДАВАТЕЛЬ (ПРЕПОДАВАТЕЛЬНИЦА), практически, по данным проведенного в колледже опроса, неразличимых в языковом сознании первокурсников.

На основе дискурс - и концептуального анализа скриптов ответов информантов был сформирован обобщённый семантический прототип идеального учителя, который включает конституенты своеобразной студенческой профессиограммы по следующему запросу: высокий уровень образованности, хорошее знание предмета, креативность, умение преподавать свой предмет нестандартно, не по шаблону, наличие чувства юмора, сдержанность, умение выслушать и способность к эмпатии; умение в «накаленных» ситуациях сохранять спокойствие, не повышать голос и уж тем более не поднимать руку на ученика/студента; скромный внешний вид.

\section{Выводы}

Следует отметить, что само составление данного семантического прототипа и одновременно кониептуальный анализ зоонимов по причине, с одной стороны, занимательной с точки зрения этносемантики выявленной лингвокутурной информации [См. 36; 37], а другой, - смысловой диффузности [См. 38] рассматриваемых концептов являются своеобразными процедурами вербального утешения, так как строятся преподавателем и одновременно квалифицированным клиническим психологом на трех известных приемах: рационализаиии, предусмотрительности и переключении [См. 14. С. 93-96].

В данном случае переключение было направлено на восприятие животных - (анимотерапия [См. 39]) и связанных с ними явлений природы, которое подкреплялось музыкотерапией - прослушиванием следующего фрагмента англоязычного песенного дискурса: Animals (Здесь и далее курсив - наш. - Д.Н., Г.И., Д.Д.)/wild rivers and waterfalls/I can hear the planet call/show a little respect/ beautiful/to everything that is beautiful/and if you want to save it all show a little respect... [37]. - (Здесь - перевод и курсив наш. - Д.Н., Г.И., Д.Д.). - Животные /дикие реки и водопады/Я слышу зов планеты/проявите немного уважения/красиво/ко всему прекрасному/и если вы хотите сохранить все это, проявите немного уважения...

Таким образом, научно-исследовательская деятельность в области аналитического и метафорического по своей природе английского языка важна для подготовки будущих медиков, так как служит средством обучения эффективным суггестивным речевым стратегиям [См. 40], т.е. охранительной по своей природе психотерапевтической риторике [См. 41].

\section{ЛИТЕРАТУРА}

1. Казыдуб Н.Н.//Дискурсивное пространство «PLANNING»: этнокультурная интерпретация// Языковые и культурные контакты различных народов. Материалы Всероссийской научно-методической конференции. - Пенза, 2003. - С. 112-114.

2. Бейлинсон Л.С. Характеристики медико-педагогического дискурса (на материале логопедических рекомендаций): Автореферат ... канд. филол. наук. Волгоград, 2001. -22 c.

3. Мелехова Г.Н. Проблемы возрождения традиционной духовности в общеобразовательных школах г. Москвы // Православие и культура этноса. Тезисы докладов. - М.: «Старый сад», 2000.- С. 197-199.

4. Рожнова К.С. Личные характеристики и показатели агрессивности подростков с различным уровнем физической активности // Вопросы наркологии.2013. - №4. - С. 64-72.

5. Прот. Алексий Касатиков, Остапенко А.А. Метки взросления как мера соответствий ступеней онтогенеза человека и иерархических ступеней общества // 
Шпаков А.Э., прот. Алексий Касатиков, Остапенко А.А., Дробышев В.В. Православная культура в современной России: монография. Отв. ред. А. Касатиков. - Краснодар: Просвещение-Юг, 2005. - С.148-154.

6. Воркачев С.Г. «Юноше, обдумывающему житье» // Что есть человек и что польза его: идея смысла жизни в лингвокультуре: монография. - Волгоград: Парадигма, 2011. - С.109-135.

7. Щербаков Э.Л. Социальные группы. Лидеры и аутсайдеры // Психология для преподавателя. Учебное пособие для слушателей факультета повышения квалификации и аспирантов. - Краснодар: Куб. гос. технол. ун-т, 1996. - С 86-98.

8. Майгур (Дикун) Н.В., Федосеев А.А., Сарычева С.А. «Достучаться до небее»: удивленное восприятие английских и русских песенных колоронимов студентами младших курсов технического вуза // СТУДЕНТ ГОДА 2018: Сборник статей VII Международного научно- исследовательского конкурса. В 2 ч. - Ч. 1. - Пенза: МЦНС «Наука и Просвещение», 2018. - С. 135-139.

9. Ермакова Г.А., Дикун (Майгур) Н.В., Баев А.А. К вопросу о повышении наркоустойчивости подростков и молодёжи: необходимость межведомственного взаимодействия, изучения и коррекции влияния субкультур // Здоровье населения - основа процветания России: Материалы VIII Всероссийской научно-практической конференции с международным участием, 24-25 апреля 2014 года. - Анапа: Изд-во РГС в г. Анапе, 2014. - С. 87-90.

10. Корепанова Е.В. Адаптация студента в диаде «преподаватель-студент» // Вести Тамбов. ун-та. Серия Гуманит. науки, 2001 - с. 54-55.

11. Агличева И.В. Адаптация и здоровье // Лучшие работы в сети по логопедии и коррекционной педагогике [Электронный pecypc]. - URL: www.superinf.ru (дата обращения: 07.05.2014).

12. Бобровская О.В., Горбачева Ю.В. Психологическое здоровье студентов колледжа [Электронный ресурс]. - URL: https://urok.1sept.ru/articles/654489 (дата обращения: 07.05.2014).

13. Дорофеева (Майгур, Дикун) Н.В. Удивление как эмоциональный концепт (на материале английского и русского языков). Автореферат ... канд. филол. наук. - Волгоград, 2002. - 19 c.

14. Авдеев Д.А., Невярович В.К. Нервность: ее духовные причины и проявления.- М.: Сестричество во имя преподномученицы Великой княгини Елизаветы, $2000-100$ c.

15. Ханский А.О. Коммуникативные стратегии вербального утешения. Автореферат ... канд. филол. наук. - Тверь, 2002. - 16 с.

16. Методики диагностики эмоциональной сферы: психологический практикум. / Сост. 0.В. Баранова.- Красноярск: Литера-принт, 2009.- 237 с.

17. Дидактогения [Электронный ресурс]. - URL: https://ru.wikipedia.org/wiki/Дидактогения (дата обращения: 07.05.2014).

18. Комолкина 0.И., Чернецкая Н.И. Психические состояния студентов-первокурсников медицинского колледжа // Известия Иркутского государственного университета. Серия: Психология. 2018. T. 23. - URL: https://cyberleninka.ru/article/n/psihicheskie-sostoyaniya-studentov-pervokursnikov-meditsinskogokolledzha (дата обращения: 07.05.2021).

19. Мирошниченко Е.А., Майгур (Дикун) Н.В. Преемственность научно-исследовательской работы в школе и вузе как средство профнавигации молодежи // Профнавигация Молодежи. Сборник материалов II Международной научно-практической конференции. 2019. - Краснодар: изд-во КубГТУ (Краснодар). - С. 86-91.

20. Баранов А.Г., Лихолетова П.В. Поликодовость дискурсивных практик // Язык. Культура. Коммуникация: материалы Международной научной конференции, г. Волгоград, 18-20 апреля 2006 г.: в 3 ч. Ч.3./ ВолГУ.- Волгоград: Волгоградское научное издательство, 2006. - С. 33-39.

21. Еротич В. Психологическое и религиозное бытие человека. - М.: Библейско-богословский институт им. Апостола Андрея, 2008. - 206 с.

22. Татаринова Л.Н. Художественный текст в парадигме католической и православной культуры. - Краснодар: Изд-во КубГтУ, 2010.- 216 с.

23. The Concise Oxford Dictionary of English Etimology. - New York: Oxford University Press, 1995. - 560 c.

24. Исторический словарь. Черепаха. Происхождение, Этимология. Библейская энциклопедия Арх. Никифора [Электронный pecypc]. - URL: https://u-jack.ru/ istoricheskii-slovar-cherepaha-proishozhdenie-etimologiya.html (дата обращения: 16.04.2021).

25. Tortoise Quotes [Электронный ресурc]. - URL: https://www.goodreads.com/quotes/tag/tortoise (дата обращения: 05.05.21).

26. Середа П.В. Амфиболия как средство реализации эстетического концепта «комическое» в русском и английском языках // Восточнославянские языки и литературы в историческом и культурном контекстах: когнитивная лингвистика и концептуальные исследования: сб. науч. ст. - Киев, 2012. -Вып.13. C. 166-173.

27. Кэрролл Л. Алиса в Стране Чудес - Льюис Кэрролл - Морские мороки продолжение [Электронный ресурс]. - URL: http://www.planetaskazok.ru/ drzarubskaz/alisavstranechudescarrolskz?start=14 (дата обращения: 09.05.2021).

28. Скойбеда У. Мучительница первая моя [Электронный ресурс].- . URL: http://www.myjulia.ru/post/518618/ (дата обращения: 09.05.2021).

29. Суд оставил "учительницу-мучительницу" без зарплаты // Вести. Южный Урал, 09.11.2016 [Электронный ресурc]. -URL: https://www.cheltv.ru/Sudostavil-uchitelnicu-muchitelnicu-bez-zarplaty/ (дата обращения: 09.05.2021).

30. Текст песни Disney - The twelve days of Christmas [Электронный ресурс]. - http://teksty-pesenok.ru/true-love/tekst-pesni-those-days/6468582/ (дата 0бращения: 09.05.2021).

31. Акафист // Википедия [Электронный ресурс]. -https://ru.wikipedia.org/wiki/Акафист (дата обращения: 09.05.2021).

32. Акафист святым и праведным Богоотцем Иоакиму и Анне. - М.: Изд-во: Пересвет, 2009. - 16 с.

33. Жанцанова М.Г., Дагбаев Д.Э. Концепт «учитель» в современной лингвистике // Вестник БГУ. Образование. Личность. 0бщество. 2019. - №2.- [Электронный ресурс] URL: https://cyberleninka.ru/article/n/kontsept-uchitel-v-sovremennoy-lingvistike (дата обращения: 07.05.2021).

34. Заречнева Е.Н. Социокультурный концепт «УЧИТЕЛь»: когнитивно-дискурсивное исследование: Автореферат ... канд. филол. наук. - Барнаул, 2009. 21 с.

35. Шевчик А.В. Образные зоонимы русского и английского языков: общность и специфика // Вестн. Том. гос. ун-та. - 2011. - №343. - URL: https:// cyberleninka.ru/article/n/obraznye-zoonimy-russkogo-i-angliyskogo-yazykov-obschnost-i-spetsifika (дата обращения: 05.05.2021).

36. Чернышев С.В. Происхождение названий животных в английском языке // Филология и лингвистика. - 2017. - № 1 (5). - C. 104-108. - URL: https:// moluch.ru/th/6/archive/45/1383/ (дата обращения: 05.05.2021). 
37. Ченки А. Конструкции, метафоры и слияние концептов // Когнитивная семантика: Материалы Второй Междунар. шк.-семинара по когнитив. лингвистике, 11-14 сент. 2000 г./ Отв. ред. Н.Н. Болдырев; Редкол.: Е.С. Кубрякова и др.: В 2 ч. Ч. 2 - Тамбов: Изд-во Тамб. ун-та, 2000.- С. 6-10.

38. Анимотерапия. // Обретаем душевное равновесие. Как переносить стрессы и депрессии: православный взгляд./0. Бычковская.- СПб: САТИСъ, 2013. C.44-46.

39. Текст песни Michael Learns to Rock - Animals [Электронный ресурс]. - URL: http://teksty-pesenok.ru/ Animals/ (дата обращения: 07.05.2021).

40. Бушев А.Б., Зиньковский А.К., Агкацева М.Г. Психотерапевтическая риторика: Монография. - Тверь: 000 «Издательство «Триада», 2013. - 256 с.

(c) Дикун Наталия Владимировна (chastity75@mail.ru), Голубев Илья Геннадьевич (jkudjo@list.ru), Демиденко Дмитрий Александрович (dimruss36@gmail.com).

Журнал «Современная наука: актуальные проблемы теории и практики» 